\title{
A palavra e o seu poder de cura: a palavra como fármaco
}

\section{Silvana Pessoa}

É sabido que o conceito de cura em psicanálise, por meio da fala, não implica total remissão de sintomas, mas sim uma transformação, uma nova forma de enlaçar, um afrouxamento do nó da neurose, um savoir-y-faire com o sintoma, ou, dizendo de outro modo, a identificação com o sintoma, naquilo que há de mais próprio em cada um. Desta forma, parece-me crucial tratar neste ensaio de um tema crucial, qual seja: a palavra como fármaco, haja vista que, dentre os que nos procuram em sofrimento para fazer uma análise, há pessoas que se curam. Mas como? Cabe aos psicanalistas investigarem e tentarem responder.

Esta é uma pergunta muito recorrente para os que iniciam uma clínica. Escuto-a no divã, vinda de alguns, e de alguns outros que acompanho em supervisões. Afirmações sensacionais do tipo: "Não sei bem o que estou fazendo, mas é fato que alguma coisa está acontecendo". Sim, está, e o que está acontecendo? Pergunta importante que jamais deveria nos abandonar, pois se somos pesquisadores neste campo, não deveríamos recuar diante da práxis da teoria; e a psicanálise não terá vida longa, certamente, se os analistas não souberem para onde aponta a direção da cura e se não questionarem o que fazem - e nestes me incluo.

Como disse Lacan diversas vezes em seus seminários, trata-se de saber como é que se sussurra ao sujeito que se tem em análise alguma coisa que tem como efeito curá-lo? Ele diz que essa é uma questão de experiência, na qual desempenha um papel que ele chamou de sujeito suposto saber. "O sujeito suposto saber é alguém que sabe. Ele sabe o truque, já que falei de trucagem” (LACAN, 1953/1998, p. 274).

Sabe-se que as respostas nas diferentes escolas serão sempre distintas quanto a este e muitos outros pontos, e por aqui, no campo lacaniano, serão muitas também, e tudo bem! Para tratar desta questão, encontrei uma interlocução interessante entre Elisabeth Thamer, psicanalista brasileira radicada na França, que escreveu uma tese (2008) sobre o estatuto sofístico da psicanálise, e Jairo Gerbase, que trata da hipótese da cura pela palavra em seu último livro Atos de fala (2015).

Ambos, Gerbase e Thamer, aproximam Freud e Lacan dos sofistas e dos enunciados performativos de John Austin (1962), filósofo inglês, discutido no livro de Barbara Casin (2012). Enunciados que fazem ser o que é dito e que podem atuar como fármaco. Nossos colegas, Thamer e Gerbase, estão de acordo em muitos pontos e em desacordo em alguns outros. Destaco aqui dois pontos, pois podem nos interessar neste ensaio. Inicia Jairo: 
Devo procurar o efeito terapêutico da fala na própria fala e não no locutor nem no referente. Devo considerar que a fala tem efeito a partir do que ele mesmo diz em análise. Thamer, diferentemente, pensa que o efeito terapêutico tem um efeito efêmero se não contar com a presença e a intervenção do analista, e que é preciso que o analista opere para que uma cura possa alcançar efeito definitivo de mudança do sujeito (GERBASE, 2015, p. 89).

Para Thamer, apenas a fala do analisando sob transferência é ato performativo, o que Gerbase não concorda. Cito-o:

Não é porque o sentido de uma interpretação tem efeitos que o analista detenha a verdade, pois os efeitos de uma interpretação são incalculáveis. Há um saber que não pensa, não calcula, não julga, mas trabalha para o gozo. [...]. Não é a palavra que sai da boca do analista que cura; não é a palavra que sai da boca do analisando que cura; é a fala que cura, certas palavras curam. De um lado a palavra é um significante da identificação; de outro é um significante da interpretação. Por um lado, a fala é um significante que faz sintoma, por outro é um significante que desfaz sintoma (Ibid., p. 91).

Para ele a direção da cura implica encontrar um enunciado performativo, um significante singular da nominação de cada sujeito, que desfaça o sintoma, um enunciado performativo que venha dissolver o sintoma pelo dito. Este é o primeiro ponto.

O segundo ponto é que para Thamer o ato não é um dito nem um dizer, não é uma ação, nem um fazer, logo não é performativo, nem performance. Para ela o ato é construído por Lacan para evidenciar que nem tudo é linguagem, e postula que ele escolheu a palavra ato para ultrapassar o limite da interpretação. Gerbase argumenta que essa hipótese defendida na sua tese é um equívoco e justifica: "No universo do falasser tudo é linguagem. Linguagem é tudo do universo simbólico, não apenas a fala, a linguagem falada, mas a cor, a imagem e é mesmo essa ideia que temos do significante. [...] neste sentido, ato é linguagem, [...], repetir é agir, é linguagem" (GERBASE, 2015, p. 50).

Debate interessante e necessário no nosso campo, um campo profícuo de pesquisa cujo modelo é o chiste.

[...] com um jogo de palavras se realiza o gozo de rir. Da mesma maneira com o sonho. Um jogo de palavras se realiza o gozo de dormir. Igualmente com o lapso, com um jogo de palavras se realiza o gozo de se envergonhar. Finalmente, com o sintoma, com um jogo de palavras se realiza o gozo de sofrer. Eis o que Lacan denominou como formações do inconsciente e o modo de operar com elas, ou seja, a prática da psicanálise foi definida 
como talking cure, chimney sweeping, catarse, sugestão e persuasão, léxicos freudianos ou tagarelice, prática de bavardage, [léxicos lacanianos] que implicam que as palavras têm consequência (Ibid., pp. 10-11).

Se a fala funda um fato - mesmo quando ela ordena, roga ou insulta -, esse fato pode ser: somatizar, temer, sofrer, ou seja, modos de dizer em ato (Ibid., p. 11), e foi Freud quem inventou um método para tratar disso. Se há falas venenos que fazem sintomas, fazem as pessoas se sentirem mal, diminuídas, humilhadas, há falas remédios, que desfazem sintomas, que modificam estados de espírito, que podem deixar alguém alegre e saltitante, precisamos saber operar com elas.

Os sofistas praticavam a equivocação muito bem, pois entendiam a fala como demiúrgica, por fazerem existir o mundo a partir das palavras e tinham habilidade de tratá-las pelo equívoco ou entender as suas propriedades transformativas, por exemplo, transformar o adjetivo redondo em um adjetivo substantivado, como redondeza sem referente.

Seja por essas propriedades transformativas, dos adjetivos substantivados sem referente (redondeza, besteira, prudência etc.), qualquer fala performativa, ou atos de fala, pode ser considerado fármaco ou veneno pelos seus efeitos; logo, aquilo que escutamos, desde sempre, ou desde a infância, é determinante para "compor" o que somos. Dizendo de outro modo, quando do enlace da palavra com o corpo algo se esboça, isso produzirá efeitos, para o melhor e para o pior. O significante é performativo (quando dizer é fazer), ele afeta o corpo, ele faz "o nó que somos nós".

Jamais se saberá precisamente quando isto se dá, pois para que a palavra tenha essa dimensão contingente, performativa, equívoca, que se inscreve em necessidade no sintoma, ela precisa ser inesperada, não calculada, contingente. Todavia, também se pode dizer que ela acontece na hora do traumatismo, no encontro com o furo (SOLER, 2010). De qualquer modo, jamais se saberá o que se fará daquilo que se diz, nem o que se transmite; é possível constatar apenas os efeitos do traumatismo, deste encontro, para agir com a mesma velocidade da língua, utilizando os seus mesmos recursos, pois "a psique humana é uma hierarquia entrelaçada em que acontecem várias voltas estranhas" (HOFSTADER, 1997).

Extraímos disso duas importantes questões: 1) se é do enlaçamento da palavra com o corpo que algo se esboça, temos duas categorias: palavra e corpo. Por outro lado, se dissermos que a palavra é corpo, temos uma só e mesma coisa. 2) o que cura é a fala endereçada ao analista ou o que cura são os enunciados performativos com as suas características? Perguntas importantes, que nos levam ao conceito de moterialismo, e, para dar conta deste intento, partirei de uma paródia.

Os cristãos repetem nos seus cultos dominicais, não necessariamente com fervor, o credo que implica uma topologia trina: "creio em Deus pai, todo-poderoso; criador do céu e da terra e em seu Filho e no Espírito Santo". O psicanalista poderia recitar um outro, que não deixa de implicar também uma trindade, qual seja: 
"creio no Real, que diz a verdade, mas não fala; no Simbólico, que diz a mentira, mas que passa a verdade quando fala e fala muito e no Imaginário que tem sempre razão, pois é sustentado pela consciência, no 'eu sei', que sustenta o falso".

Desta maneira, Lacan enunciou, numa aula de 15/02/1977, o conteúdo de $A$ carta roubada, que não se sabe qual é, mas não importa, pois o que conta é o reconhecimento desse saber que sustenta o jogador. Um saber que não implica a verdade ou a falsidade, mas que implica o reconhecimento da MOTerialidade, um prematuro encontro da palavra com o corpo, um tipo de mais-de-gozar, que leva a dizer "isso é alguém”, ou seja, um enlaçamento particular do RSI, um nó borromeano, logo uma posição da primeira questão, palavra enlaçada num corpo.

Na Conferência em Genebra sobre o Sintoma, Lacan (1975/inédito) diz deste enlaçamento assim: "pelo modo como a alíngua foi falada e também ouvida por tal e qual na sua particularidade, que alguma coisa em seguida reaparecerá nos sonhos, em todo tipo de tropeços, em todas as espécies de modo de dizer, em que reside a tomada do inconsciente, o que faz com que cada um não tenha encontrado outros modos de sustentar a não ser o que há pouco chamei sintoma”. Sintoma que ata os três registros: Real, Simbólico e Imaginário.

Os princípios da moterialidade, como enlaçamento definido em 1975, estão presentes desde 1947, quando Lacan afirma, em Formulações sobre a causalidade psíquica, que "a linguagem do homem, esse instrumento da sua mentira, é atravessada de ponta a ponta pelo problema da sua verdade" e que "a palavra [mot] não é signo, mas nó de significação. Uma palavra pode designar muitas coisas além do objeto; pode ser uma coisa por metáfora, uma outra por trocadilho" (Ibid., p. 167). Logo, palavra sempre equivoca enlaçada em um nó.

No texto Função e campo (1953/1998) temos um belo exemplo das múltiplas possibilidades de sentido das palavras e como elas identificam cada um dos seres: os devas, os homens e os assuras. Estes três grupos, ao terminarem seu noviciado com Prajapati, pediram que este lhes falasse, e, o deus do trovão disse simplesmente: "Da". E o que se fez ouvir? Para os devas, submissão; para os homens, dom, e para os assuras, perdão. "Da, da, da”. Submissão, dom, perdão. "Vós me ouvistes", concluiu o deus hindu.

Não importa o significado do "Da", ou o conteúdo da carta, quando o jogador sabe a regra do jogo, sabe o truque. Toda linguagem é equívoca, matéria, substância-gozante, corpo - entendo aqui a justa defesa de Gerbase - e não estímulos substitutivos que se utilizam no lugar de coisas, um organon, como define Aristóteles, palavras com sentidos unívocos, pautadas pelo princípio da não contradição. Neste ponto, entendo que posso dizer que a palavra é corpo e que ela, enlaçada num corpo, faz nó, faz sintoma, faz o que somos. Resta ainda o exame da palavra e do seu poder de cura, da palavra como fármaco.

Freud (1891/1979) sacou este funcionamento, essa regra do jogo, essa trucagem desde seu primeiro ensaio a Interpretação das afasias, e Lacan o referendou em 
Função e campo dizendo que "a técnica não pode ser aprendida, nem corretamente aplicada quando se desconhece os conceitos que a fundamentam" (LACAN, 1953/1998, p. 274). Quais sejam? Os recursos da língua: a materialidade das palavras, dos sons, a função poética, ou seja, mais a forma como transmitimos (combinação das palavras, pronúncias, efeitos sonoros e rítmicos) do que a função referencial ou denotativa (o assunto ou o conteúdo de uma informação).

Difícil apreender este funcionamento, principalmente porque os analisantes trazem as narrativas, usam muito mais a função denotativa, visam transmitir um contexto, uma situação, tentam fazer prosa e esquecem que falar é compor versos, fazer uso de pausas, ritmos e tons. Mas se os analistas lacanianos não reconhecerem o "credo", que se extrai do RSI, o nó próprio de cada um, este "tipo de mais-de-gozar, que leva a dizer 'isso é alguém', estar-se-á num caminho longe de chegar a um material dialético talvez mais ativo que a carne do partido" (LACAN, 1970/2003, p. 413).

Arrisco a dizer que alguns neurologistas já reconhecem este material dialético. Eles entendem que muitos aspectos de nossos processos cognitivos, disposição para aprendizagem e memória se baseiam em inferências inconscientes, em processos que ocorrem sem que tenhamos consciência deles. Eles constatam como alguns tipos de experiências repetidas ficam codificadas na memória procedural (KANDEL, 2009, p. 405).

Para mostrar o que tento transmitir com este trabalho, de como a linguagem (palavras, sons, cores, imagens) afeta o corpo, tratarei de um caso - tal como fez Freud com Schreber -, de um testemunho publicado em umlivro intitulado Em busca da memória, escrito por um neurocientista, Nobel em 2000, Eric Kandel, e também da sua fala no documentário Em busca da memória. ${ }^{1}$ Vamos ao caso.

Neste documentário, Kandel, um neurocientista vienense naturalizado americano, visita lugares da sua infância e rememora fatos mais traumáticos. Ele explica com isso como a interação com outros ou as lembranças de fatos podem mudar a nossa estrutura cerebral, principalmente numa psicoterapia, em que experiências passadas podem ser revividas de outro lugar, numa idade mais velha e num ambiente mais protegido. Ele demonstra como experiências vividas com mais intensidade transformam os estímulos bioquímicos nas células, fortalecem a memória de longa duração e a aprendizagem.

O que é possível concluir após ler o livro e assistir ao documentário é que há influência do vivido naquilo que somos, e que nós, psicanalistas, precisamos ainda fazer mais um esforço para demonstrar que essas experiências são de linguagem, pois é a linguagem que faz a coisa, ela que está disponível, seja em experiências

1 Disponível em https://www.youtube.com/watch?v=afZ5MFc2whE. A referência começa do ponto 29:26" do vídeo, onde Kendal diz: "let's get inside" até 58:12" quando diz: "I am going swiming". 
sensoriais, cheiro ou cor (olhar ou voz), ela tem corpo, ela muda o corpo; e a $M A$ TERIAlidade do ser humano deve ser procurada na propriedade desse corpo que é falar, que é fazer uso do significante, assim o humano aprende e se torna aquilo que é. Foi por isso que Lacan denominou de parlêtre, que em português costuma-se a traduzir por falasser.

A substância do falasser é a fala. Fazendo metalíngua, Lacan traduziu o dazain heideggeriano por être l'a, ser o $a$. Desse modo, ele reuniu fala e objeto para poder definir a materialidade do ser, não como consistência imaginária, mas como consistência lógica (GERBASE, 2015, p. 42). Por isso se dá importância aos recursos da língua e da poesia, e até mesmo a ideia de que as palavras são corpo, quem sabe, para promover cadeias e sinapses como se vê no videodocumentário. Arrisco dizer que vi ali a mostração de uma "moterialidade gozada" (SOLER, 2010, p. 25), em que a palavra é corpo, corpo sutil, mas corpo, e a linguagem, campo.

Destaco algumas falas de analisandos para interrogar as questões postas neste ensaio. 1) alguém no divã diz, ao falar sobre efeitos da sua análise: “algo destravou quando você disse um dia, num tom moderado, 'é preciso falar'; enquanto que na análise anterior, eu pensava, mas não falava”. Será que dá para inferir com essa passagem que o tom utilizado pelo analista, mais do que o enunciado, liberou a fala para que ela mesma operasse como fármaco?; 2) Alguém, no início de uma sessão, diz: "me deu branco!", e prossegue dizendo: "Em algum momento algo deslocou aqui na minha posição, aconteceu uma disjunção - a fala não é fala, mas efeito de fala... não sei nomear o que aconteceu aqui... sei que deu uma volta. Ter me aproximado da morte, mesmo que seja a de um outro, teve uma dimensão de beleza, de fugacidade. Talvez por isso o branco do início da sessão”. Seria aqui a própria fala e o silêncio entre as palavras enunciadas que atuaram como fármaco?; 3) "Quando me descolo do outro ou do que as pessoas me demandam, sinto que o dispêndio de energia muda. Mas, às vezes, caio no mesmo padrão, um certo gozo masoquista, e vejo que mais uma vez estou me sacrificando". Seria aqui um funcionamento, o gozo masoquista, que fica registrado no sistema nervoso, tal como uma "moterialidade gozada"?

Mais um exemplo desta moterialidade, que faz pensar, pode ser extraído do caso em questão. As lembranças de Kandel no documentário, relatadas com riso ou lágrimas - principalmente quando escuta música ou quando lembra da atrocidade feita por "pessoas refinadas" contra os judeus - aproximam-se do afeto de perda (do brinquedo) e da dor (pelo desaparecimento de pessoas queridas), mesmo que a sua história seja boa (foi bem acolhido nos Estados Unidos, tem uma família amorosa, realizou-se no trabalho). No entanto, esse afeto, que não cessa de se escrever, esse encontro prematuro com o corpo, que levou Kandel a "fazer o seu nó”, o seu sintoma, aquilo que lhe é mais próprio, pode levá-lo a ter uma constante curiosidade pelo entrelaçamento da mente com o corpo, da psicologia com 
as neurociências e com a biologia molecular. O sintoma, aqui entendido como resultado desta marca mnêmica, uma memória permanente, que foi construída sobre um primeiro significante originário, a perda (a subtração súbita do carro azul), mas que também se liga à falta estrutural, o significante do trauma que não tem nenhuma espécie de sentido.

O significante do trauma é um $S(X)$, um significante que não é um significante incluso no Outro, que se fixou nas contingências dos encontros de gozo. Ora, em si mesmo ele não tem nenhuma espécie de sentido, ele [Lacan] vai, aliás, renomeá-lo. Traço Unário; e teria sido preciso dizer desde já que ele era do inconsciente real, salvo que Lacan postulava, então, que ele fazia cadeia com os significantes da demanda. Está, portanto, bem certo que mesmo enquanto ele afirmava o inconsciente estruturado como uma cadeia, Lacan postulava sua ancoragem na moterialidade de um significante fora de sentido, aquele mesmo que o dedo apontado da Direção da cura [...] designava (SOLER, 2010, pp. 29-30 - chave nossa).

O sinthoma - este extraído ao final da direção da cura já estava desde o início - é o seu nó, seu nome próprio, seu poema, haja vista que o maior interesse de Kandel foi fazer o entrelaçamento da psicologia com a neurociência, foi dar continuidade ao trabalho de Freud. Ele nunca conseguiu se curar da dor da perda do carrinho azul, retirado dele de forma estúpida, mas conseguiu transformar a dor, numa estúpida e talvez divertida existência. Ele achou a sua forma de enfrentar e se divertir na vida.

O livro e o documentário em questão tiveram um fim, e as análises também terão. Mas resta uma questão: se na direção do tratamento o analista opera pelo sentido ou significação, não sem levar em conta o real, o sem-sentido em jogo em cada atendimento, como fazer com que o final de uma análise não seja tão difícil e utópico, especialmente para os que conhecem ou praticam a psicanálise, essa constante balança entre verdade e real, entre o gozo do sentido e o gozo daquilo que o tampona e que faz ali como que um contrapeso? Trago uma referência que me orienta nesta questão.

Ora, a análise, inconsciente real ou não, opera por e no nível do dizer. Em outras palavras, nós somos poema, ou seja, sinthoma, o sintoma-letra aí estando incluído, mas não identificável, a não ser a título hipotético. É isso que a referência final à poesia implica. Somente ali onde o poeta faz cálculo do equívoco para produzir um dizer que lhe seja próprio, o dizer de seu poema; pois bem, o analista não pode fazer igual, ele não pode calcular sua interpretação, a verdade sendo tão incalculável quanto o real. Ele vai 
ali, portanto, a esmo, "todos os lances são permitidos". Além disso, ele tem que lidar com um poema que não é o seu, e que ele não conhece, mas que lhe pedem, eventualmente, para corrigir. Então, para levar em conta esse poema como real, sinthoma, ele se utiliza, em seu dizer, de um outro real, o da alíngua e de seus equívocos, os quais podem jogar contra o gozar do poema, já que é por eles que o poema se fez.

Não obstante, remanejar o poema - isto é, o nó - não é, necessariamente, corrigir o gozo opaco, nem encontrar a palavra do real. A análise é o que faz verdade, mas está excluído que ela faça verdade do real. Então, retificar o poema é amarrar de outra forma, por nó [épissure] - sutura, diz Lacan -, e isso consiste, antes, a mudar não o núcleo opaco ininterpretável, do qual tudo indica que ele permanece opaco, mas a balança entre verdade e real, entre o gozo do sentido e o gozo daquilo que o tampona e que faz ali como que um contrapeso. É por essa razão que Lacan não disse que, no passe, vinha-se testemunhar do real, mas da verdade mentirosa. Não se testemunha do real tampouco quanto não se interpreta dele, dado que testemunhar dele ou interpretá-lo seria fazê-lo passar à verdade. Aliás, podemos constatar que a partir de 1975-1976, todas as elaborações de Lacan consistem em explorar modificações possíveis do enodamento sob o efeito do dizer analítico, esse dizer que não é o do analista, é o que resulta dos efeitos do equívoco interpretativo sobre o dizer analisante. Sua morte põe ali um termo, sem dúvida, prematuro, em que o momento de concluir que fica em suspenso deixa um certo sentimento de algo inacabado (Ibid., s/n).

Explorar modificações possíveis do enodamento sob o efeito do dizer analítico, a trucagem que o analista opera e que resulta dos efeitos do equívoco interpretativo sobre o dizer do analisante, a palavra como fármaco; eis o que me parece importante pesquisar e apontar neste nosso campo, na nossa clínica, num encontro que trata dos problemas cruciais da atualidade, cuja medicalização tem sido muito utilizada para tratar de problemas dos seres falantes.

\section{Referências bibliográficas}

AUSTIN, J. How to do things with words? Cambridge: Harvard University Press, 1962. CASIN, B. Jacques le shophiste Lacan, logos e psychanalise. Paris: Epel Editions, 2012. GERBASE, J. Atos de fala. Salvador: Associação Científica Campo Psicanalítico, 2015. HOFSTADER, D. Godel, Escher e Bach: laços eternos. Lisboa: Gradiva Portugal, 1979.

KANDEL. E. Em busca da memória. São Paulo: Companhia das Letras, 2009. 
LACAN, J. (1953) Função e campo da fala e da linguagem. In: Escritos. Rio de Janeiro: Jorge Zahar Ed., 1998.

. (1972-73) O seminário, livro 20: mais ainda. Rio de Janeiro: Jorge Zahar Ed., 1992.

(1970) Radiofonia. In: Outros escritos. Rio de Janeiro: Jorge Zahar Ed., 2003.

(1975) Conferência em Genebra sobre o sintoma. Disponível em: http:// www.campopsicanalitico.com.br/media/1065/conferencia-em-genebra-sobre-o-sintoma.pdf._Acesso em: 25 maio 2017.

. (1976-77) L'insu que sait de l'une-bévue s'aile à mourre. Disponível em: http://www.campopsicanalitico.com.br. Acesso em: 25 maio 2017.

SOLER, C. Uma interpretação que leve em conta o real. In: Stylus: Revista de Psicanálise, n. 24. Rio de Janeiro, 2010.

THAMER E. Lacan e a Sofística: sobre o estatuto sofístico da psicanálise. Tese (Doutorado - École Doctorale "Concept et language") - Universidade de Paris - Sorbonne, Paris, 2015.

VERDIGLIONE, A. Matemática do inconsciente. In: FREUD, S. (1891). A interpretação das afasias. Lisboa: Edições 70, 1979.

\section{A palavra e o seu poder de cura: a palavra como fármaco The word and its healing power: the word as a drug}

\section{resumo}

Esse artigo tenta investigar como, pela operação do significante, há pessoas que se curam, mesmo que o analista não seja possuído pelo desejo de curar. Para responder esta questão, a autora trabalha o conceito de moterialismo, da palavra como fármaco, e faz uma articulação disso com as novas descobertas das neurociências, particularmente desenvolvidas pelo neurocientista Eric Kandel. Esse ensaio defende que o sujeito suposto saber é alguém que sabe o truque de como se cura uma neurose sem o uso de medicações, mas que para isso é necessário que este esteja referenciado pelos conceitos que a fundamentam, ou seja, os recursos da língua: a materialidade das palavras, dos sons, a função poética, ou seja, mais a forma como transmitimos (combinação das palavras, pronúncias, efeitos sonoros e rítmicos) do que a função referencial ou denotativa (o assunto ou o conteúdo de uma informação).

\section{palavras-chave:}

Lacan; neurociência; moterialismo, palavra, fármaco. 


\section{abstract}

This article tries to investigate in what manner, by the operation of the signifier, there are people who cure themselves, even though the analyst is not possessed by the desire to cure. To answer this question, the author works on the concept of moterialism, the word as a drug, and articulates this with the new discoveries by the neurosciences, particularly those developed by neuroscientist Eric Kendal. This essay defends that the analyst is someone who knows the trick of how to cure a neurosis without the use of medications. In order to do this, it is necessary that the analyst is referenced by the nature of the language - the materiality of words, the sounds, the poetic function, the way people communicate (combination of words, pronunciations, sound and rhythmic effects) more than by the referential or denotative function of their speech (the subject or content of a piece of information).

\section{keywords:}

Lacan; neuroscience; moterialism; word; drug.

\section{Recebido:}

23/05/2017

\section{Aprovado:}

27/06/2017 